American Journal of Applied Sciences 6 (8): 1489-1494, 2009

ISSN 1546-9239

(C) 2009 Science Publications

\title{
Synthesis and Optical Properties of $\mathrm{ZnO}^{-\mathrm{TeO}_{2}}$ Glass System
}

\author{
H.A.A. Sidek, S. Rosmawati, Z.A. Talib, M.K. Halimah and W.M. Daud \\ Department of Physics, Faculty of Science, University Putra Malaysia, \\ 43400 UPM Serdang, Selangor, Malaysia
}

\begin{abstract}
Problem statement: Systematic series of $\mathrm{ZnO}-\mathrm{TeO}_{2}$ glasses with mole fraction of $0.10-0.40$ $\mathrm{ZnO}$ content with an interval of 0.05 were studied to obtain their physical and optical properties. Approach: All the glass samples were synthesized by rapid melting quenching method under controlled conditions, while their refractive indices (n) were measured by the EL X-02C high precision ellipsometer. The room temperature absorption of all glass samples were determined using Camspec M350 double beam UV-visible spectrophotometer. The infrared (IR) spectra of each glass samples were recorded with Thermo Nicolet Fourier Transform-Infrared (FT-IR) spectrophotometer. Their physical properties were measured and the amorphous nature was confirmed by the x-ray diffraction technique. Results: The increase of refractive index of the $\mathrm{TeO}_{2}-\mathrm{ZnO}$ glasses with the addition of $\mathrm{ZnO}$ was best explained in terms of either electron density or polarizability of the ions. The absorption edge shift to higher energy (shorter wavelength) with increasing $\mathrm{ZnO}$ content was observed in this glass. The optical band gap $\left(\mathrm{E}_{\mathrm{opt}}\right)$ of zinc tellurite glass decreases with increasing of $\mathrm{ZnO}$ content probably due to the increment of Non-Bridging Oxygen (NBO) ion contents which eventually shifted the band edge to lower energies. Conclusion/Recommendation: The physical and optical properties of zinc tellurite glasses were found generally affected by the changes in the glass composition. FTIR spectra of zinc tellurite glass revealed broad, weak and strong absorption bands in the investigated range of wave numbers from 4000-400 $\mathrm{cm}^{-1}$ which associated with their corresponding bond modes of vibration and the glass structure. The addition of $\mathrm{ZnO}$ into $\mathrm{TeO}_{2}$ glass network shifted the major band from $626 \mathrm{~cm}^{-1}$ (for pure $\mathrm{TeO}_{2}$ glass) to the band at around $669 \mathrm{~cm}^{-1}$.
\end{abstract}

Key words: Glass synthesis, tellurite glass, optical materials, optical properties

\section{INTRODUCTION}

Tellurite glasses have been intensive studied because of their technological and scientific importance. Such amorphous materials are candidates for new optical materials because of their superior properties, such as high refractive index, high dielectric constants, a wide band infrared transmittance and large third order non-linear optical susceptibility ${ }^{[1,2]}$. Moreover they posses relatively low transformation temperatures, high densities and non hygroscopic properties, which limit the application of phosphate and borate glasses ${ }^{[3,4]}$. Therefore these glasses are suitable as host for active element doping, represent the main justification for their continuous technological interest in areas of optoelectronics such as laser technology, optical fibers, non-linear optical devices and sensor systems $^{[1,5]}$.

The $\mathrm{TeO}_{2}-\mathrm{ZnO}$ system shows good and stable glass-forming ability with a broad region. However this glass formation strongly depends on the cooling rate and the size of the melt, especially in the $\mathrm{TeO}_{2}$-rich region $^{[6]}$. The $\mathrm{ZnO}-\mathrm{TeO}_{2}$ system was used as a basis for multi-component optical glass synthesis and has been reported as a useful medium for ultra-low loss $\left(1 \mathrm{~dB} 1000 \mathrm{~m}^{-1}\right)$ optical fibers for wavelengths in the 3.5-4 $\mu \mathrm{m}$ region $^{[5]}$. The above mentioned indicate undoubtedly the existence of a practical interest in the zinc-tellurium containing systems as a choice of compositions for super heavy optical flint glasses ${ }^{[1,4]}$.

Apart from their applications, there is a lack of data on structural investigations of these glasses in the literature. Therefore the objectives of this research are to study the physical and optical properties of $\mathrm{ZnO}$ $\mathrm{TeO}_{2}$ glass system and compare with those past studies which will ultimately help us understand the fundamental origin of their properties. This study reports our work on the investigation of the physical and optical properties of binary zinc tellurite glass system.

Corresponding Author: H.A.A. Sidek, Department of Physics, Faculty of Science, University Putra Malaysia, 43400 UPM Serdang, Selangor, Malaysia. Email: sidek@ science.upm.edu.my 
Am. J. Applied Sci., 6 (8): 1489-1494, 2009

\section{MATERIALS AND METHODS}

In this study, glass samples were synthesized by rapid melting quenching method. The binary system consists of $(\mathrm{ZnO})_{\mathrm{x}}\left(\mathrm{TeO}_{2}\right)_{1-\mathrm{x}}$ with $\mathrm{x}=0.1$ to $\mathrm{x}=0.4$ in the interval of 0.05 is shown in Table 1 . The binary glasses were prepared from commercial powders by mixing the specific weights of batches using tellurium (IV) oxide, $\mathrm{TeO}_{2}$ (Technical grade, Alfa Aesar) and zinc oxide, $\mathrm{ZnO}$ (99.99\%, Assay, Alfa Aesar). The glass starting materials were weighted using electronic balance. For pre-melting process, a lidded alumina crucible which contained a well mixed $20 \mathrm{~g}$ batches was then preheated in a first furnace to $400^{\circ} \mathrm{C}$ for $30 \mathrm{~min}$ in order to evaporate water vapor and to remove any gases in the mixture.

The batch materials was then transferred to a second electric furnace and kept at $750-800^{\circ} \mathrm{C}$ for $1 \mathrm{~h}$. During the process, the crucible was slightly shaken using metal holder several times to ensure homogeneity and proper mixing. All the melting processes were done using electric furnace manufactured by Lindberg, Thermolyne and Bole. After the melting process, each melt was quenched rapidly into cylindrical stainless steel split mould which had been preheated at $400^{\circ} \mathrm{C}$ in order to relieve the mechanical stress in sample for glass casting process. The samples form a glass rod with $2.0 \mathrm{~cm}$ height and $1.1 \mathrm{~cm}$ diameter. After casting, each glass samples was immediately transferred to an annealing furnace at $350^{\circ} \mathrm{C}$ and slowly cooled to room temperature before they kept in the desiccators.

These samples were then cut by using the Isomet Low Speed Saw machine and polished using various grades of silicon carbide abrasive paper to obtain the parallel, smooth and clear surface for experiment. The thickness of the glass specimens was measured using a digital micrometer gauge. The X-ray diffraction analysis for each glass samples was carried out using a computer-controlled X'pert Pro Panalytical with CuK a radiation source $(\lambda=1.5418 \stackrel{0}{\mathrm{~A}}), 40 \mathrm{kV}$ accelerating potential and $30 \mathrm{~mA}$ tube current. The scanning was carried out from $5-50^{\circ}$ at step width of $0.02^{\circ}$. The density of each glass samples was determined using Archimedes' principle by using acetone as floatation medium. Acetone is not absorbed by and does not react with the hygroscopic glass composition, its low surface tension discourages bubbles of air from adhering to the sample during immersion. The molar volume of each glass samples were then calculated by using the molecular weight of the substance and the true density of the glassy material. Detail of glass sample preparation is found elsewhere ${ }^{[7,8]}$.
Table 1: Variation of density and molar volume of the $\mathrm{ZnO}_{(\mathrm{x})} \mathrm{TeO}_{2(1-\mathrm{x})}$ glasses system

\begin{tabular}{|c|c|c|c|c|}
\hline \multirow[b]{2}{*}{ Glass sample } & \multicolumn{2}{|c|}{ Mole fraction } & \multirow{2}{*}{$\begin{array}{l}\text { Density } \\
\left(\mathrm{kg} \mathrm{m}^{-3}\right)\end{array}$} & \multirow{2}{*}{$\begin{array}{l}\text { Molar volume } \\
\left(\mathrm{cm}^{3} \mathrm{moL}^{-1}\right)\end{array}$} \\
\hline & $\mathrm{x}$ & $1-\mathrm{x}$ & & \\
\hline TZ0 & 0.00 & 1.00 & 4806 & 33.21 \\
\hline TZ1 & 0.10 & 0.90 & 5098 & 29.77 \\
\hline TZ2 & 0.15 & 0.85 & 5102 & 28.98 \\
\hline TZ3 & 0.20 & 0.80 & 5136 & 28.03 \\
\hline TZ4 & 0.25 & 0.75 & 5194 & 26.96 \\
\hline TZ5 & 0.30 & 0.70 & 5211 & 26.13 \\
\hline TZ6 & 0.35 & 0.65 & 5280 & 25.04 \\
\hline TZ7 & 0.40 & 0.60 & 5283 & 24.29 \\
\hline
\end{tabular}

The EL X-02C High Precision Ellipsometer was used to measure the refractive indices (n) of the glasses. Measurements were performed at room temperature with helium-neon laser beam of $632.8 \mathrm{~nm}$ wavelength as the light source. For this measurement each glass samples were cut and polished to obtain $0.2 \mathrm{~cm}$ thickness. The room temperature absorption of all glass samples were determined using Camspec M350 Double Beam UV-Visible Spectrophotometer instrument. The infrared (IR) spectra of each glass samples were recorded with Thermo Nicolet Fourier TransformInfrared (FT-IR) spectrophotometer in the frequency range $400-4000 \mathrm{~cm}^{-1}$ with $2 \mathrm{~cm}^{-1}$ resolution at room temperature.

\section{RESULTS AND DISCUSSION}

The systematic binary zinc tellurite glasses samples with mole fraction of $0.10-0.40 \mathrm{ZnO}$ content with an interval of 0.05 were well prepared using a meltquenched method under controlled conditions. Each of good quality glass samples is free from bubbles, transparent and slightly yellow in color.

The density and the molar volume of the studied glasses are shown in Table 1 where the density of glass increases from $4806-5283 \mathrm{kgm}^{-3}$ with the substitution of $\mathrm{TeO}_{2}$ by $\mathrm{ZnO}$, while molar volume decreases from 33.208 to $24.287 \mathrm{~cm}^{3} \mathrm{~mol}^{-1}$. As expected addition of $\mathrm{ZnO}$ to the tellurite network causes some type of structural rearrangement of the atoms. There is a possibility for the alteration of the geometrical configuration upon substitution of $\mathrm{ZnO}$ into the tellurite glassy network.

The increase in density indicates that the zinc ions enter the tellurite glass network which is related to variation of the molar volume of the samples. The decreases in the molar volume is due to the decrease in the bond length or inter-atomic spacing between the atoms which may be attributed to the increase in the stretching force constants $\left(216-217.5 \mathrm{~N} \mathrm{~m}^{-1}\right)$ of the bonds inside the glass network. Hence the radius of $\mathrm{Zn}^{2+}(0.074 \mathrm{~nm})$ is much smaller than that of $\mathrm{Te}^{2+}$ $(0.097 \mathrm{~nm})^{[9]}$ resulting in a more compact and dense glass. 
As reported from previous works, the addition of $\mathrm{ZnO}$ that consist of $\mathrm{Zn}^{2+}$ will modify the tellurite glass structure by creating more non-bridging oxygen (NBOs) in the network ${ }^{[2]}$. $\mathrm{ZnO}$ which acts as network modifier will break up the continuous network and the divalent cation $\mathrm{Zn}^{2+}$ will then produce two non-bridging oxygen's ions each. The degree of crosslinking in those glasses is progressively degraded as the mole fraction of $\mathrm{ZnO}$ increases. As a result of the non-directed bonding to cations, the structural network collapses into closer packing and hence the density increases ${ }^{[8]}$. The NBOs created were believed to alter the glass structure in a way that packing of the molecule becomes denser as more network modifier ions, attempt to occupy the interstices within the network. An increase of the density of the glasses accompanying the addition of $\mathrm{ZnO}$ is probably caused to a change in crosslink density and coordination number of $\mathrm{Te}^{2+}$ ions ${ }^{[10]}$.

The XRD pattern of each binary zinc tellurite glass samples obtained is shown in Fig. 1.

As shown in Fig. 1, all the glass samples were found to show no discrete or continuous sharp peaks but exhibit broad halo at around $2 \Theta \cong 26-30^{\circ}$, which reflected the characteristic of amorphous glass structure. This indicates the absence of long range atomic arrangement and the periodicity of the three dimensional network in the quenched material. The absence of sharp, strongly diffracted beams in the X-ray diffraction patterns from glass indicated that there were no well defined planes in the structure on or around which the constituent atoms were regularly arranged.

Table 2 shows the refractive index of the $\mathrm{TeO}_{2}$ $\mathrm{ZnO}$ glasses which increases from 1.963-2.100. The average refractive index of present zinc tellurite glass is 2.009. The molar refraction $\left(\mathrm{R}_{\mathrm{M}}\right)$ and refractive index $n$ primarily depend on the polarizability of the material. As can be seen from Table 2, the molar refractivities decrease from $16.502-12.724$ while the polarizability decreases from $6.542 \times 10^{-24}-5.044 \times 10^{-24} \mathrm{~cm}^{3}$ with the increase of concentration of $\mathrm{ZnO}$. The use of the molar refractivity stresses the role of ionic packing in controlling the refractive index of a glass. Since the refractive index is proportional to the molar refractivity divided by the molar volume, it is obvious that a small molar volume will yield a larger refractive index for a glass consisting of ions of similar polarizabilities.

By knowing the chemical composition of the glass and its density, the number of atoms per unit volume $(\mathrm{N} / \mathrm{V})$ can be calculated which mainly depends on the modifier content. However, these changes are not sufficient to account for the observed increase in the refractive index. With substitution of $\mathrm{ZnO}$ oxides into $\mathrm{TeO}_{2}$, bridging Te-O-Te bonds are broken and nonbridging Te-O- $\mathrm{Zn}^{2+}$ bonds are formed ${ }^{[1]}$. The non-

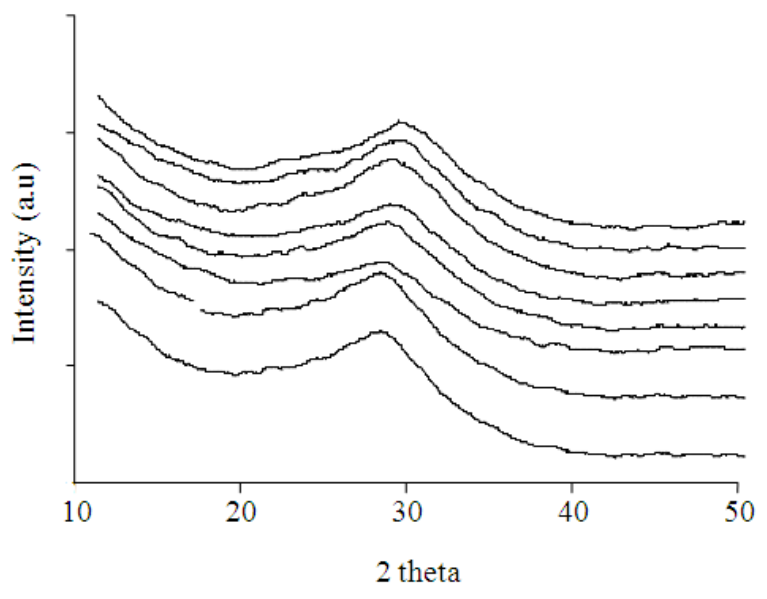

Fig. 1: The XRD patterns of binary zinc tellurite and pure tellurite glass (TZ0)

Table 2: Refractive indices, molar refractivity and polarizability of zinc tellurite glasses

\begin{tabular}{|c|c|c|c|}
\hline Glass sample & $\begin{array}{l}\text { Refractive } \\
\text { index } \mathrm{n} \\
( \pm 0.01)\end{array}$ & $\begin{array}{l}\text { Molar } \\
\text { refractivity } R_{M} \\
( \pm 0.01)\end{array}$ & $\begin{array}{l}\text { Polarizability } \\
\alpha\left(\times 10^{-24}\right) \\
( \pm 0.01)\end{array}$ \\
\hline TZ0 & 1.99 & 16.50 & 6.54 \\
\hline TZ1 & 1.96 & 14.52 & 5.75 \\
\hline TZ2 & 1.97 & 14.20 & 5.63 \\
\hline TZ3 & 1.98 & 13.83 & 5.48 \\
\hline TZ4 & 1.99 & 13.39 & 5.31 \\
\hline TZ5 & 2.00 & 13.14 & 5.21 \\
\hline TZ6 & 2.07 & 13.32 & 5.28 \\
\hline TZ7 & 2.10 & 12.72 & 5.04 \\
\hline
\end{tabular}

bridging oxygen (NBO) bonds have a much greater ionic character and much lower bond energies. Consequently, the NBO bonds have higher polarizability and cation refractions.

An addition in either electron density or polarizability of the ions will cause an increase in the refractive index (n) of materials ${ }^{[11]}$. If $\mathrm{ZnO}$ as a second oxide is added to $\mathrm{TeO}_{2}$ networks formed from the corner-connected $\mathrm{TeO}_{4}$ units, the modification process start with rupture of Te-O-Te bridges and change of the two participating $\mathrm{TeO}_{4}$ to $\mathrm{TeO}_{3}$ units, each of latter having two NBOs. Among the samples studied by Hoppe et al. ${ }^{[11]}$, only that with $22 \mathrm{~mol} \% \mathrm{ZnO}$ shows this behavior. Further increasing the modifier content stabilizes $\mathrm{TeO}_{4}$ units with non-bridging oxygen (NBO).

Figure 2 shows the optical absorption spectra in arbitrary units of $\mathrm{TeO}_{2}-\mathrm{ZnO}$ glass samples obtained in the wavelength range of $200-800 \mathrm{~nm}$. It is clear that there is no sharp absorption edge which correspond the characteristic of the glassy state. Generally, the absorption edge of these glasses is determined by the oxygen bond strength in the glass-forming network. Any change of oxygen bonding in the glass network, 
for instance, the formation of non bridging oxygen, changes the characteristic absorption edge.

It has been reported that the UV transmittance of $\mathrm{ZnO}$ edge shifts to shorter wavelengths with increasing $\mathrm{ZnO}$ content in binary tellurite glasses ${ }^{[8]}$. In this study, the position of the fundamental absorption edge shifts to lower energy (higher wavelength) with increasing $\mathrm{TeO}_{2}$ content in the glass system. The shift of the ultraviolet absorption band to longer wavelengths corresponds to transitions from the NBO which bound an excited electron less tightly than the bridging oxygen $^{[9]}$. The general appearance of the absorption spectra of the present glasses is similar as found by Burger et al. ${ }^{[8]}$.

In many crystalline and non-crystalline semiconductors, the $\alpha(\omega)$ depends exponentially on the $\hbar \omega$. This exponential dependence, known as the Urbach rule, can be written as:

$\alpha(\omega)=B \exp \left(\frac{\hbar \omega}{\Delta E}\right)$

Where:

$\mathrm{B}=$ The constant

$\Delta \mathrm{E}=$ The width of the band tails of the localized states

In general both direct and indirect transitions can occur in a semiconducting material. The smallest gap leads to direct transition. The indirect transition is associated with a smaller a.

For many glasses and amorphous materials, $\alpha$ is given by:

$\alpha(\omega)=\mathrm{B}\left(\hbar \omega-\mathrm{E}_{\mathrm{opt}}\right)^{\mathrm{n}} / \hbar \omega$

with $\mathrm{n}=2$ is found to represent the experimental results and this case applies to indirect allowed transitions in such materials when the electron wave vector $\mathrm{k}$ is no longer a good quantum number ${ }^{[12]}$. of:

The data for Fig. 3 was obtained from the relation

$(\alpha \hbar \omega)^{1 / 2}=$ const $\left(\hbar \omega-\mathrm{E}_{\mathrm{opt}}\right)$

The indirect energy band gap is determined from linear region of the plot as shown in the Fig. 3 and corresponding values are shown in Table 3 . The results show that the indirect band gap values are decreasing with decrease of $\mathrm{TeO}_{2}$ content. This result suggests that the covalent nature of the glass matrix decreases with increase of $\mathrm{ZnO}$ content. The values of optical band gap varies from $2.34-1.88 \mathrm{eV}$ for $\mathrm{n}=2$. It is known that the concentration of the non-bridging oxygen ions decreases with increasing $\mathrm{TeO}_{2}$.

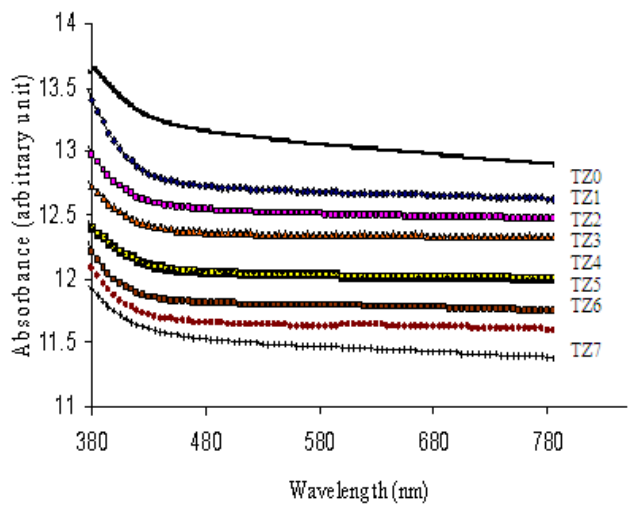

Fig. 2: Optical absorbance spectra for $(\mathrm{ZnO})_{\mathrm{x}}\left(\mathrm{TeO}_{2}\right)_{1-\mathrm{x}}$ glasses

Table 3: Optical band gap of zinc tellurite glasses, $\left(\mathrm{TeO}_{2}\right)_{1-\mathrm{x}}(\mathrm{ZnO})_{\mathrm{x}}$.

\begin{tabular}{llll}
\hline Glass sample & $\begin{array}{l}\text { Sample } \\
\text { thickness } \\
( \pm 0.01) \mathrm{mm}\end{array}$ & $\begin{array}{l}\text { Optical band } \\
\text { gap }\left(\mathrm{E}_{\text {opt }}\right)(\alpha \hbar \omega)^{1 / 2} \\
( \pm 0.01) \mathrm{eV}\end{array}$ & $\begin{array}{l}\text { Urbach energy } \\
( \pm 0.01) \mathrm{eV}\end{array}$ \\
\hline TZ0 & 2.00 & 2.34 & 0.85 \\
$\mathrm{TZ1}$ & 2.48 & 2.61 & 0.60 \\
$\mathrm{TZ2}$ & 1.96 & 2.56 & 0.71 \\
$\mathrm{TZ3}$ & 1.91 & 2.51 & 0.82 \\
$\mathrm{TZ4}$ & 1.96 & 2.49 & 0.80 \\
$\mathrm{TZ5}$ & 1.98 & 2.20 & 1.45 \\
$\mathrm{TZ6}$ & 1.98 & 2.18 & 1.50 \\
TZ7 & 1.97 & 1.88 & 1.91 \\
\hline
\end{tabular}

Table 3 shows the variation of $\mathrm{E}_{\mathrm{opt}}$ with composition for $\mathrm{ZnO}-\mathrm{TeO}_{2}$ glasses where the values of $\mathrm{E}_{\mathrm{opt}}$ decrease linearly with increasing $\mathrm{ZnO}$ content. Such variation can be explained by suggesting that the NBO ion content increases with increasing $\mathrm{ZnO}$ content, shifting the band edge to higher energies and leading to a decrease in the value of $\mathrm{E}_{\mathrm{opt}}$.

Table 3 also shows the Urbach energy value for prepared glasses was found to lie between 0.85 $1.91 \mathrm{eV}$. The exponential dependence of absorption coefficient $\mathrm{a}(\omega)$ on photon energy $(\hbar \omega)$ as shown in Fig. 4 suggests that these materials obey Urbach rule. An addition of $\mathrm{TeO}_{2}$ to the glass system shows reduction in optical band gap as well as Urbach tails with the densification of the glass network.

As reported by earlier workers, the FTIR spectra for crystalline $\mathrm{TeO}_{2}$ exhibits two absorption bands at 778 and $669 \mathrm{~cm}^{-1}$ which has been ascribed to the stretching vibration of equatorial and axial Te-O bonds in the $\mathrm{TeO}_{4}$ units, respectively ${ }^{[13]}$. As shown in Fig. 5, the strong band which is located at $626 \mathrm{~cm}^{-1}$ and the weak band at $760 \mathrm{~cm}^{-1}$ are the characteristics of the tellurite glass and attributed to vibrations of $\mathrm{TeO}_{4}$ tetragonal pyramids. The wave number of the FTIR spectra of zinc tellurite glasses of present study is 


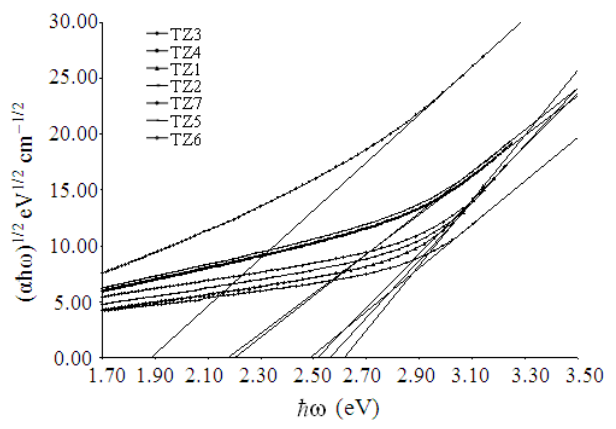

Fig. 3: Plot of $(\alpha \hbar \omega)^{1 / 2}$ against photon energy $\hbar \omega$ for indirect band gap measurement

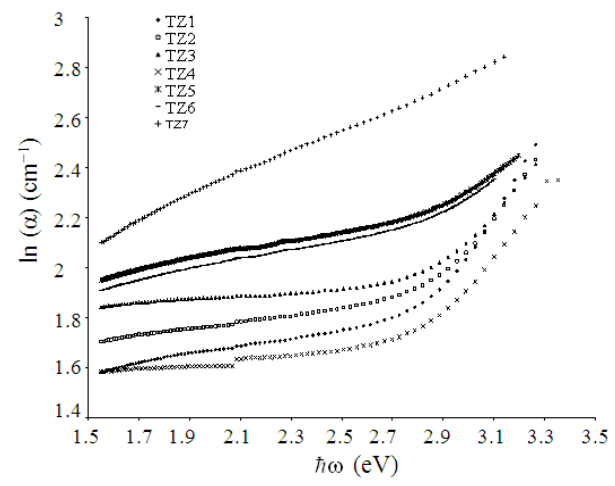

Fig. 4: $\ln (\alpha)$ as a function of $\hbar \omega$ for zinc tellurite glasses

shown in the Table 4. Zinc oxide connected to the chains of $\mathrm{TeO}_{4}$ groups identified on the basis of the simultaneous presence of the band at around $668 \mathrm{~cm}^{-1}$ which shifted the major band from $626 \mathrm{~cm}^{-1}$. Those major bands have been ascribed to the stretching vibration of equatorial and axial Te-O bonds in the $\mathrm{TeO}_{4}$ tbp and $\mathrm{TeO}_{3}$ tp unit ${ }^{[1]}$.

This broad peak also ascribed to the mixing structures of $\mathrm{TeO}_{3}$ groups, symmetric $\mathrm{TeO}_{4}$ groups and deformed $\mathrm{TeO}_{4}$ groups. The peaks shift toward higher wave number region as the $\mathrm{ZnO}$ content gradually increased. However, the frequency shifts of the peaks are small due to the influence of $\mathrm{Zn}^{2+}$ on breaking tellurium-oxygen networks is also small ${ }^{[1]}$.

There is another small peak found at around 745$675 \mathrm{~cm}^{-1}$ as due to $\mathrm{TeO}_{3}$ trigonal pyramids which strengthened upon the addition of $\mathrm{ZnO}$ to the glass content in agreement with those observations reported previously. The modifier cation enters the glass lattice network by breaking up the Te-O-Te bonds (the oxygen atoms of modifier break the local symmetry while $\mathrm{M}^{2+}$ (where $\mathbf{M}=$ modifier cation) ion occupy interstitial positions) introduces coordinated defects known as dangling (broken) bonds in these glasses ${ }^{[14]}$.

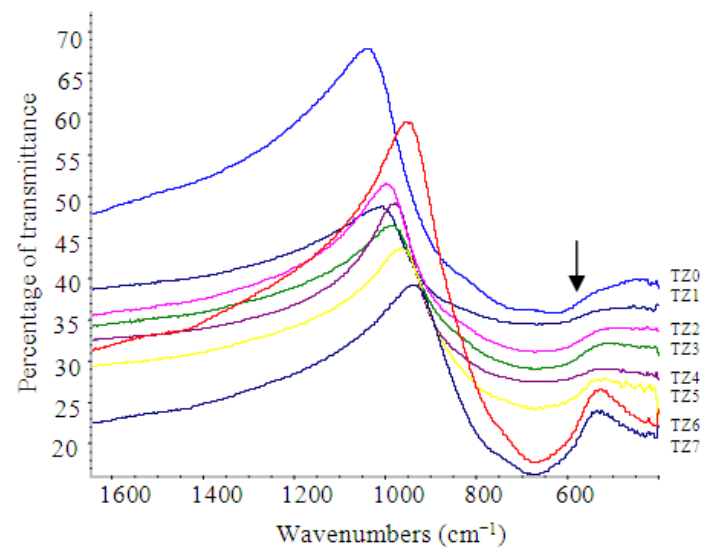

Fig. 5: FTIR spectra of $\left(\mathrm{TeO}_{2}\right)_{1-\mathrm{x}}(\mathrm{ZnO})_{\mathrm{x}}$ glasses with various compositions

Table 4: FTIR peaks position of the $(\mathrm{Zn} \mathrm{O})_{\mathbf{x}}\left(\mathrm{TeO}_{2}\right)_{1-\mathrm{x}}$ glasses

\begin{tabular}{lll}
\hline Glass sample & $\mathrm{TeO}_{2}+\mathrm{ZnO}$ & IR bands $\left(\mathrm{cm}^{-1}\right)$ \\
\hline TZ0 & $100.0+0.0$ & $444 ; 626 ; 760$ \\
TZ1 & $90.0+10.0$ & $443 ; 668 ; 745$ \\
TZ2 & $85.0+15.0$ & $457 ; 669 ; 726$ \\
TZ3 & $80.0+20.0$ & $441 ; 668 ; 684$ \\
TZ4 & $75.0+25.0$ & $428 ; 675 ; 718$ \\
TZ5 & $70.0+30.0$ & $431 ; 668 ; 730$ \\
TZ6 & $65.0+35.0$ & $429 ; 665 ; 675$ \\
TZ7 & $60.0+40.0$ & $428 ; 675 ; 685$ \\
\hline
\end{tabular}

During this process there can be different ways of forming dangling bonds in the present glass: (i) The stable $\mathrm{Te}-\mathrm{O}$ and (ii) The unstable $\mathrm{Te}-\mathrm{O}$ (or simply $\mathrm{TeO}_{3+1}$ ) owing to the contraction of one Te-O and the elongation of another Te-O bond. With increasing modifier content, cleavage of continuous network leads to an increase in the fraction of $\mathrm{TeO}_{3+1}$ polyhedra. Further the elongation of the $\mathrm{Te}-\mathrm{O}$ bond of $\mathrm{TeO}_{3+1}$ and its cleavage finally lead to the formation of trigonal prismatic $\mathrm{TeO}_{3}$ units. Thus the structure of the present $\mathrm{ZnO}-\mathrm{TeO}_{2}$ glass network is an admixture of $\mathrm{TeO}_{4}$, $\mathrm{TeO}_{3+1}$ and $\mathrm{TeO}_{3}$ units.

Previous study showed that $\mathrm{Zn}$ enter into $\mathrm{TeO}_{2}$ by the evidence of the vibration and the absorption peaks position shift from $443-428 \mathrm{~cm}^{-1}$ with the increases of the $\mathrm{ZnO}$ content ${ }^{[8]}$. It can also noted that a lot of additional small intensity peaks in the spectra of the glass samples in the range $420-450 \mathrm{~cm}^{-1}$ appear as $\mathrm{ZnO}$ content increase. Those small peaks occur due to the deformation of the Te-O bond vibration.

\section{CONCLUSION}

The physical and optical properties of zinc tellurite glasses were found generally affected by the changes in 
the glass composition. The densities of the binary zinc tellurite glasses increases as the $\mathrm{ZnO}$ content was added to substitute the $\mathrm{TeO}_{2}$ content while molar volume decreases. The increased in density were probably because of the decreased in average inter atomic spacing. The refractive index of the $\mathrm{TeO}_{2}-\mathrm{ZnO}$ glasses increase with substitution of $\mathrm{ZnO}$ oxides into $\mathrm{TeO}_{2}$, bridging Te-O-Te bonds are altered and non-bridging $\mathrm{Te}-\mathrm{O}-\mathrm{Zn}^{2+}$ bonds are formed. The non-bridging oxygen (NBO) bonds have a much greater ionic character and much lower bond energies. The UV transmittance of $\mathrm{ZnO}$ edge shifts to shorter wavelengths with increasing $\mathrm{ZnO}$ content. The movement of the UV absorption band corresponds to the transitions from the NBO which bound an excited electron less tightly than the BO. The values of $\mathrm{E}_{\mathrm{opt}}$ for indirect allowed transition decrease linearly with the increase of $\mathrm{ZnO}$ content. These results can be explained by the creation of NBOs. The FTIR spectra of $\mathrm{TeO}_{2}-\mathrm{ZnO}$ showed that the strong band which was located at $626 \mathrm{~cm}^{-1}$ was shifted to $669 \mathrm{~cm}^{-1}$ with the existence of $\mathrm{ZnO}$ content. The modifiers enters the glass lattice network by breaking up the Te-O-Te bonds introduces coordinated defects in these glasses.

\section{ACKNOWLEDGEMENT}

We like to thanks the Ministry of Science, Technology and Innovation of Malaysia who provided the financial support for this research project under the eScience Fund Scheme.

Part of this paper has been presented at the $8^{\text {th }}$ PACRIM Conference on Ceramic and Glass Technology, May 31- June 5, 2009 at Vancouver, Canada.

\section{REFERENCES}

1. El-Mallawany, R.A., 2002. Tellurite Glasses Handbook, Physical Properties and Data. CRC Press, Baca Raton, FL., ISBN: 0849303680, pp: 540.

2. Khattak, G.D. and M.A. Salim, 2002. X-ray photoelectron spectroscopic studies of zinc-tellurite glasses. J. Elect. Spectroscopy Relat. Phenomena, 123: 47-55. DOI: 10.1016/S0368-2048(01)00371-1

3. Sabry, A.I. and M.M. El-Samanoudy, 1995. Optical, infrared and electrical conductivity of glasses in the $\mathrm{TeO}_{2}-\mathrm{B}_{2} \mathrm{O}_{3}$ system. J. Mater. Sci. 30: 3930-3935.

http://www.cheric.org/research/tech/periodicals/vol _view.php?seq=136422

4. El-Mallawany, R., 1998. Review. Tellurite glasses Part 1 elastic properties. J. Mater. Chem. Phys. 53: 93-120. DOI: 10.1016/S0254-0584(97)02041-5
5. Ravi kumar, V. and N. Veeraiah, 1997. Infrared spectral investigations on $\mathrm{ZnF}_{2}-\mathrm{PbO}-\mathrm{TeO}_{2}$ glasses. J. Mater. Sci. Lett., 16: 1816-1818. http://cat.inist.fr/?aModele=afficheN\&cpsidt=2100359

6. Kozhukharov, V., S. Neov, I. Gerasimova and P. Mikula, 1986. Neutron diffraction investigation of a tellurite-tungstate glass. J. Mater. Sci., 21: 17071714. DOI: $10.1007 / \mathrm{BF} 01114729$

7. Van Uitert, L.G. and S.H. Wemple, 1978. $\mathrm{ZnCl}_{2}$ glass: A potential ultra-low optical fiber material. Applied Phys. Lett., 33: 57-59. DOI: 10.1063/1.90189

8. Sidek, H.A.A., S.P. Chow, Z.A. Talib and S.A. Halim, 2004. Formation and elastic behavior of leadmagnesium chlorophosphate glasses. Turk. J. Phys., 28: 65-71.

http://journals.tubitak.gov.tr/physics/issues/fiz-0428-1/fiz-28-1-8-0301-5.pdf

9. Bürger, H., K. Kneipp, H. Hobert, W. Vogel, V. Kozhukharov and S. Neov, 1992. Glass formation, properties and structure of glasses in the $\mathrm{TeO}_{2}-\mathrm{ZnO}$ system. J. Non-Crystalline Solid, 151: 134-142. http://scripts.iucr.org/cgibin/paper?iz3022

9. Shelby, J.E., 2005. Introduction to Glass Science and Technology. The Royal Science of Chemistry. 2nd Edn., United Kingdom, Cambridge, ISBN: 978-1-84755-116-0.

10. El-Adawy, A. and Y. Moustafa, 1999. Elastic properties of bismuth borate glasses. J. Phys. D. Applied Phys., 32: 2791-2796.

http://iopscience.iop.org/0022-3727/32/21/312

11. Hoppe, U., E. Yousef, C. Russel, J. Neuefeind and A.C. Hannon, 2004. Structure of zinc and niobium tellurite glasses by neutron and X-ray diffraction. J. Phys. Condense Mater., 16: 1645-1663. http://iopscience.iop.org/09538984/16/9/013/?ejredirect=.iopscience

12. Al-Ani, S.K.J., C.A. Hogarth and R.A. El-Mallawany, 1985. A study of optical absorption in tellurite and tungsten-tellurite glasses. J. Mater. Sci., 20: 661-667. DOI: 10.1007/BF01026540

13. Dimitriev, Y., V. Dimitrov and M. Arnaudov, 1983. IR spectra and structures of tellurite glasses. J. Mater. Sci., 18: 1353-1358. DOI: 10.1007/BF01111954

14. Berthereau, A., Y. Le Luyer, R. Olazcuaga, G. Le Flem, M. Couzi, L. Canioni, P. Segonds, L. Sarger and A. Ducasse, 1994. Nonlinear optical properties of some tellurium (IV) oxide glasses. Mater. Res. Bull., 29: 933-941. http://cat.inist.fr/?aModele $=$ afficheN\&cpsidt $=423474$ 